https://www.amerabra.org; https://fspu.uitm.edu.my/cebs; https://www.emasemasresources.com/ $9^{\text {th }}$ Asian Conference on Environment-Behaviour Studies Perdana Kota Bharu, Kelantan, Malaysia, 28-29 Jul 2021

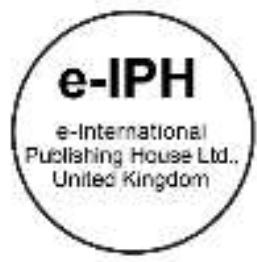

\title{
Reward and Satisfaction: Keeping hospitality employees loyal
}

\author{
Nurfatihah Mazlan¹, Norzuwana Sumarjan¹, Nadia Hanin Nazlan¹, Dwi Suhartanto² \\ ${ }^{1}$ Department of Hotel Management, Faculty of Hotel and Tourism Management, Universiti Teknologi MARA Cawangan Selangor, \\ Malaysia, \\ ${ }^{2}$ Department of Business Administration, Commerce Administration, Politeknik Negeri Bandung, Bandung, Indonesia \\ fatihahmazlan@uitm.edu.my,norzu161@uitm.edu.my, nadiahanin@uitm.edu.my, dwi.suhartanto@polban.ac.id \\ Tel: +60173234024
}

\begin{abstract}
Employee loyalty is influenced by job satisfaction which stems from various factors such as reward, work environment, or leadership. Due to the importance of loyal employees in maintaining the competitive advantage of organisation, this study examines how reward in upper-upscale hospitality organisations in Selangor influences job satisfaction and employee loyalty. Structural equation modeling using SmartPLS found significant paths between financial rewards, job satisfaction, and employee loyalty. The same could not be said for non-financial rewards. The findings provide insights into how hoteliers can strategise their financial reward and maximise non-financial reward usage to retain the employees, especially during turbulences.
\end{abstract}

Keywords: Financial reward; non-financial reward; job satisfaction; employee loyalty

eISSN: 2398-4287@ 2021. The Authors. Published for AMER ABRA cE-Bs by e-International Publishing House, Ltd., UK. This is an open access article under the CC BYNCND license (http://creativecommons.org/licenses/by-nc-nd/4.0/). Peer-review under responsibility of AMER (Association of Malaysian Environment-Behaviour Researchers), ABRA (Association of Behavioural Researchers on Asians/Africans/Arabians) and cE-Bs (Centre for Environment-Behaviour Studies), Faculty of Architecture, Planning \& Surveying, Universiti Teknologi MARA, Malaysia.

DOI: https://doi.org/10.21834/ebpj.v6i17.2817

\subsection{Introduction}

The tourism industry is one of the major contributors to Malaysia economy as it creates jobs, drives exports, and generates prosperity (Yong, 2019). Before the emergence of Covid-19, the tourism industry's total contribution to the nation's Gross Domestic Product was RM240.2 billion in 2019 (Mahidin, 2020). Out of all 14 states in Malaysia, Selangor is the most vibrant and accessible state, contributing the highest value to the tourism industry. With the number of tourist arrival in Selangor increased to 33 million in 2019 (Department of Statistic Malaysia, 2019), the state saw the expansion of major hotel brands and boutique hotels. Thus, the hotel industry is expecting an increase in the number of employments.

Labour intensive is one of the hospitality industry characteristics (Fathy, 2018). Hospitality organisations globally face high turnover and are unable to retain employees due to the nature of the industry (Dwesini, 2019). Similarly, in Malaysia, the loyalty issue continues to hamper the hotel industry (MAH Selangor, 2018). Hotel players still have problems holding onto their employees due to the inability to determine the factors that affect job satisfaction and poor implementation of best human resources practices (Jagun, 2015). Ismail and Ahmed (2015) found that a poorly structured reward and recognition demotivate and have caused disloyalty among Malaysian employees. To further support, Nurlita (2018) claimed that a study by Jobstreet.com Malaysia in 2017 showed that job dissatisfaction is due to insufficient reward, specifically salary raises and recognition. As such, dissatisfied employees could bring plenty of problems to hotel management and operations. For instance, potential unauthorise leave by unsatisfied employees (Cholli et al., 2017) or, in the worst case,

eISSN: 2398-4287@ 2021. The Authors. Published for AMER ABRA cE-Bs by e-International Publishing House, Ltd., UK. This is an open access article under the CC BYNCND license (http://creativecommons. org/licenses/by-nc-nd/4.0/). Peer-review under responsibility of AMER (Association of Malaysian Environment-Behaviour Researchers), ABRA (Association of Behavioural Researchers on Asians/Africans/Arabians) and CE-Bs (Centre for Environment-Behaviour Studies), Faculty of Architecture, Planning \& Surveying, Universiti Teknologi MARA, Malaysia.

DOI: https://doi.org/10.21834/ebpj.v6i17.2817 
walk away from organisation. As a result, operation departments will be short-handed, causing burnout to current employees and incur additional costs to pay for overtime. Thus, finding strategies to keep employees motivated, satisfied and loyal remains the primary concern in the hotel industry (Alqusayer, 2016).

\subsection{Objective of Study}

This study investigates the influence of reward (financial and non-financial) on loyalty among hotel employees, focusing specifically on salary raise and recognition. Additionally, this study examines the mediating effect of job satisfaction between reward and employee loyalty, as seen in Figure 1.

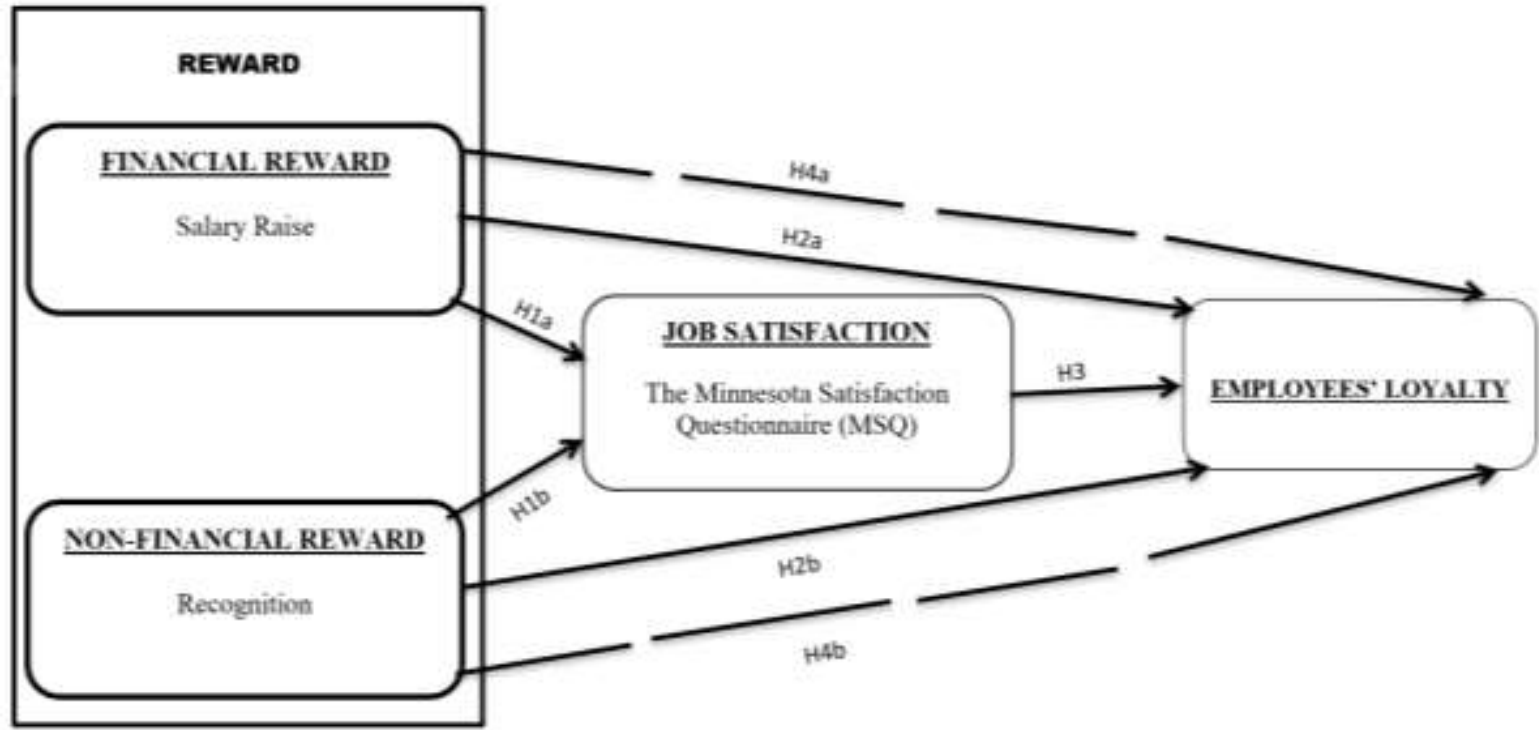

Fig. 1: Research framework of reward, job satisfaction and, employee loyalty (Source: Bustamam, Teng \&Abdullah, (2014), Cook \& Wall, (1980) and Weiss, Dawis, England \& Lofquist, (1967)

\subsection{Literature Review}

\subsection{The influence of reward on job satisfaction}

Reward and recognition can be defined as initiative given by an organisation to appreciate the contributions of employees for being a role model or positive actions (Ndungu, 2017). It is one of the many factors which lead to job satisfaction. Jose (2015) found that reward management practices motivate the employees and increase job satisfaction. In the scope of the hospitality industry, reward is positively linked to job satisfaction among hotel employees (Bustamam et al., 2014). Specifically, there is plenty of past research that linked financial reward with job satisfaction (Huang, 2016; Khan \& Afzal, 2016; Met et al., 2015). Apart from financial rewards, recognition, compliments, appreciation, and encouragements are vital for employees and employers because they lasted longer than financial rewards and usually are given exclusively to a person (Fisher, 2015).

Nevertheless, the hospitality industry is currently consisting of a multigeneration workforce (Stephens, 2020). Additionally, the industry also sees millennials as a major workforce alongside other generations in 2020 (Serrano, 2020), and generation Z is gradually filling up entry-level positions. This situation adds up to distinctive expectations and characteristics from various generations in the hospitality industry. Specifically, Calk and Patrick (2017) claimed millennials seek benefits in non-financial such as work experience and environment, rather than salary alone. Meanwhile, Generation Z is more realistic about their work expectation (Gaidhani et al., 2019). This demonstrates an opposite expectation from older generations, such as Generation X, who value monetary rewards (Stephens, 2020). Hence, the management needs to understand the reward strategy that fits all generations to boost job satisfaction, leading to employee loyalty. Therefore, this study proposed the following hypotheses:

$\mathrm{H1}$ a: Financial reward influences job satisfaction among hotel employees

$\mathrm{H} 1$ b: Non-financial reward influences job satisfaction among hotel employees

\subsection{The influence of reward on loyalty}

A good-fit human resource practice in the hotel industry increases job satisfaction and limits alternative employment options to create loyal employees. Typically, employees who are satisfied with the reward and work environment are loyal and have no intention to leave the company (Strenitzerova \& Achimsky, 2019). In addition, if employees had given considerable years of service to the hotel, the employer should reward them for their loyalty (Sekyi et al., 2016). Studies related to reward and employee loyalty in the hospitality industry were tested in various countries. In Taiwan, reward implementation influences the willingness to stay with the organisation among hotel employees (Ya-Hsin \& Hung-Sheng, 2017). In the Malaysian hotel industry, there is limited study relating to reward and 
employee loyalty. Chan et al. (2012) discovered that the reward has a significant impact on employee's loyalty working in Perak hotels. Podolinsky (2013) highlighted that eventhough Asians were more motivated by salary raises, the non-financial reward is vital too. According to Forbes, 79 percent of employees left their company due to a lack of recognition (Herlinda, 2017). Hence, service companies such as hotels should recognise that loyal employees are essential assets for the company and adapt various methods to motivate and reward the employees' contribution (Tomic et al., 2018).

This study proposed the following hypotheses:

$\mathrm{H} 2 \mathrm{a}$ : Financial reward influences loyalty among hotel employees

$\mathrm{H} 2 \mathrm{~b}$ : Non-financial reward influences loyalty among hotel employees

\subsection{The influence of job satisfaction on loyalty}

One of the main factors which contribute to loyalty is job satisfaction (Prabhakar, 2016). According to Thi and Trung (2020), when the organisation provides employees with the opportunity to learn and grow, job satisfaction is achieved and, in return, creating loyal employees. Moreover, not only satisfied employees have lesser complaints and highly focus on work, they are also more likely to continue cooperating with supervisors and organisations (Raziq \& Maulabakhsh, 2015). Past studies have found an association between job satisfaction and loyalty in the hospitality industry (Chen et al., 2017; M. Farrukh et al., 2020). However, these studies have different demographic profiles and cultures. Thus, this study aimed to investigate the influence of job satisfaction on loyalty among hotel employees in Malaysia, leading to this proposed hypothesis.

H3: Job satisfaction influences loyalty among hotel employees

\subsection{The mediating role of job satisfaction}

The mediating effect of job satisfaction between various variables appeared in several studies, but it is limited in the hospitality industry. Research by Ali et al. (2016) discovered that job satisfaction mediates the relationship between reward and turnover intentions in private higher learning institutions. According to Khan and Afzal (2016), job satisfaction also mediates the relationship between reward and employee performance in the telecommunication industry in Pakistan. Based on the discussion, it is sensible to state that job satisfaction is a significant choice for a mediator in this study. Hence the following hypothesis is formulated.

$\mathrm{H} 4_{\mathrm{a}}$ : Job satisfaction mediates the relationship between financial reward and loyalty

H4a: Job satisfaction mediates the relationship between non-financial reward and loyalty

\subsection{Methodology}

\subsection{Study design}

This was a cross-sectional study that utilised the quantitative approach through the deployment of questionnaires. The sample of the study was employees working in operation departments in five-stars hotels in Selangor, Malaysia. Partial least squares structural equation modeling was conducted for hypotheses testing by using SmartPLS version 3. The data analysis was divided into two steps, including measurement model evaluation and structural model evaluation.

\subsection{Instrumentation}

The questionnaire was adapted and designed in five sections. Financial, non-financial items and, five-point Likert scale were adapted from Bustamam et al. (2014). Among questions asked include satisfaction on recent salary raise and the frequency and fairness of recognition given. Job satisfaction items and five-point Likert scale were adapted from Weiss et al. (1967). Among questions asked include satisfaction with supervisors, co-workers, work environment, increment, and recognition. Employee loyalty items and five-point Likert scales were adapted from Cook and Wall (1980). Among questions asked include pride working with company and intention to stay with the company during financial turndown. Demographic items were developed by the author consisting six items comprised of gender, age, status, education level, monthly salary, and job tenure.

\subsection{Data collection}

Before distributing questionnaires, a questionnaire review was conducted by three experienced managers in the hotel industry and one academician from the hospitality field. Their reviews were significant to ensure the structured questions were highly understandable, correctly communicate to respondents, and provided subjective judgement on how these items accurately represented the objective of the study. A pilot test was conducted with 30 hotel employees who were later exempted from the actual data collection. The result of the pilot test achieved a reliability value of more than 0.7 , which was deemed acceptable (Sekaran \& Bougie, 2009). The list of five-stars hotels in Selangor was derived from the website of Malaysia Association of Hotel (MAH) as at 2019. The author contacted representatives in the human resource department of eleven five-stars hotels to explain the study and approval purpose. Questionnaires in the form of a booklet were given to representatives of the hotels. Only eight hotels managed to provide feedback, which brought 211 valid responses for data analysis. 


\subsection{Findings}

\subsection{Demographic profile}

The demographic profile of 211 respondents is analyzed in Table 1.

Table 1. Analysis of Demographic Profile

\begin{tabular}{llll}
\multicolumn{4}{c}{ Table 1. Analysis of Demographic Profile } \\
\hline \multirow{3}{*}{ Gender } & & $N$ & Percentage (\%) \\
Marital status & Male & 107 & 50.7 \\
& Female & 104 & 49.3 \\
Age & Single & 93 & 44.1 \\
& Married & 89 & 42.2 \\
& Others & 29 & 13.7 \\
& $18-20$ & 15 & 7.1 \\
\multirow{5}{*}{ Education level } & $21-30$ & 72 & 34.1 \\
& $31-40$ & 68 & 32.2 \\
& $41-50$ & 41 & 19.5 \\
Monthly income & $51 \geq$ & 15 & 7.1 \\
& SPM & 108 & 51.2 \\
Job tenure & Diploma & 58 & 27.5 \\
& Bachelor Degree & 29 & 13.7 \\
& Others & 16 & 7.6 \\
& RM1,000-RM2,000 & 89 & 42.2 \\
& RM2,001-RM2,500 & 58 & 27.5 \\
& More than RM2,501 & 64 & 30.3 \\
& $<1$ year & 21 & 10.0 \\
& 1 year-3 years & 88 & 41.7 \\
& 4 years-6 years & 50 & 23.7 \\
& $>6$ years & 52 & 24.6 \\
\hline
\end{tabular}

The demographic profile demonstrates a balance response from males and females. Most of the respondents were single, aged 21 to 30 years old, with SPM academic qualification. The respondents also mostly earned RM1,000 to RM2,000 per month and have worked one to three years in the hotel industry.

\subsection{Measurement model evaluation}

The process to validate this reflective measurement model at the initial stage involved examining internal consistency reliability (composite reliability) and convergent validity (average variance extract). Table 2 demonstrates the finding of composite reliability (CR) and average variance extract (AVE). The result shows high levels of internal consistency reliability as CR for each construct exceeds the recommended value of 0.7 (Hair et al., 2017). Apart from that, the recommended value for AVE is above 0.5 (Wong, 2019). All constructs except job satisfaction have exceeded 0.5. Nevertheless, according to Fornell and Larcker (1981), if the AVE value is below 0.5 , but the value of $C R$ is higher than 0.6 , the convergent validity of the construct is still adequate.

Table 2. Finding of $\mathrm{CR}$ and $\mathrm{AVE}$

\begin{tabular}{llll}
\hline Construct & Cronbach's Alpha & Composite Reliability (CR) & Average Variance Extract (AVE) \\
\hline Financial reward & 0.86 & 0.89 & 0.53 \\
Non-financial reward & 0.91 & 0.92 & 0.57 \\
Job satisfaction & 0.92 & 0.93 & 0.44 \\
Employee Loyalty & 0.90 & 0.92 & 0.67 \\
\hline
\end{tabular}

Additionally, the study established discriminant validity through the Heterotriat-Monotrait Ratio of Correlations (HTMT). Table 3 shows the finding of HTMT. According to Garson (2016), Heterotrait correlations must be smaller than Monotrait correlations, implying that the HTMT ratio should be below 1.0. The finding shows that HTMT values were below the threshold value of 0.90 , as suggested by Henseler et al. (2015). Thus, the result established discriminant validity.

Table 3. Finding of HTMT

\begin{tabular}{lllll}
\hline Construct & Financial reward & Job satisfaction & Employee loyalty & Non-financial reward \\
\hline Financial reward & & & & \\
Job satisfaction & 0.74 & 0.86 & & \\
Employee loyalty & 0.77 & 0.90 & 0.79 & \\
Non-financial reward & 0.65 & &
\end{tabular}

\subsection{Structural model evaluation}

Once the measurement model is established, a structural model was evaluated through coefficient of determination $\left(R^{2}\right)$, effect size (f2.), predictive relevance $\left(\mathrm{Q}^{2}\right)$, and path co-efficient.

\subsubsection{Coefficient of determination $\left(\mathbf{R}^{2}\right)$}

The $R^{2}$ value for job satisfaction was 0.78 , which indicated $78 \%$ change in job satisfaction is explained by financial reward and non-financial reward. Additionally, the $\mathrm{R}^{2}$ value of employee loyalty was 0.69 , which implied $69 \%$ variance in employee loyalty was explained by job 
satisfaction, financial reward, and non-financial reward. Hence, the value of $\mathrm{R}^{2}$ obtained was at a substantial level (Henseler et al.,2009; Sarstedt \& Mooi, 2014).

\subsubsection{Effect size (f2.)}

The strength of each exogenous variable in explaining endogenous variables is measured using the $\mathrm{f}^{2}$. According to Cohen (1988), values higher than $0.02,0.15$, and 0.35 indicate small, medium, and large f2 effect sizes. This study found the effect size of financial reward into job satisfaction as medium and into loyalty as small. The effect size of non-financial reward into job satisfaction is found large. However, no effect is found into employee loyalty. The job satisfaction effect size into employee loyalty was found medium.

\subsubsection{Predictive relevance $\left(Q^{2}\right)$}

According to Hair et al. (2011), the structural models are considered to have predictive relevance when $\mathrm{Q}^{2}$ greater than zero. The study found that the value of $\mathrm{Q}^{2}$ for job satisfaction was at 0.315 and loyalty was at 0.429 , respectively. Thus, the result supported predictive relevance.

\subsubsection{Path coefficient}

The bootstrapping method which runs at 5000 sub-sample with a $1.96 \mathrm{t}$-value and 0.05 significance level is used to determine the path coefficient. The finding of the path coefficient value was used to test the hypotheses. Table 4 shows the result of the hypotheses testing. Results demonstrate all hypotheses were supported except for $\mathrm{H} 2 \mathrm{~b}$. The finding did not support the influence of non-financial reward on employee loyalty as the t-value was less than 1.96 and the $p$-value was more than 0.05 .

\begin{tabular}{|c|c|c|c|c|c|c|}
\hline Hypothesis & Path & Beta & Standard deviation & T-statistics & P-value & Result \\
\hline $\mathrm{H} 1_{\mathrm{a}}$ & Financial reward $\rightarrow>$ Job satisfaction & 0.722 & 0.028 & 25.789 & 0.000 & Supported \\
\hline $\mathrm{H} 1_{b}$ & Non-financial reward $\rightarrow$ Job satisfaction & 0.851 & 0.018 & 47.529 & 0.000 & Supported \\
\hline $\mathrm{H} 2_{\mathrm{a}}$ & Financial reward $\rightarrow$ Employee loyalty & 0.217 & 0.058 & 3.747 & 0.000 & Supported \\
\hline $\mathrm{H} 2 \mathrm{~b}$ & Non-financial reward $\rightarrow$ Employee loyalty & 0.166 & 0.088 & 1.873 & 0.061 & Not Supported \\
\hline $\mathrm{H} 3$ & Job satisfaction $\rightarrow$ Employee loyalty & 0.478 & 0.075 & 6.339 & 0.000 & Supported \\
\hline
\end{tabular}

\subsubsection{Mediation analysis}

The study used the bootstrapping method, which runs at 5000 sub-sample with a 1.96 t-value and 0.05 significance level to test the mediation effect. Table 5 shows the mediating effect of job satisfaction on the relationship between financial reward and employee loyalty. The indirect effect for $\mathrm{H}_{4}$ a was significant $(t>1.96, p<0.05)$. Similarly, job satisfaction also mediated the relationship between non-financial reward and employee loyalty. The indirect effect for $\mathrm{H} 4_{b}$ was significant $(t>1.96, p<0.05)$. Thus, $\mathrm{H} 4_{a}$ and $\mathrm{H} 4_{b}$ were supported.

Table 5. Finding of mediation analysis

\begin{tabular}{lllllll}
\hline Hypothesis & Path & Beta & Standard deviation & T-statistics & P-value & Result \\
\hline $\mathrm{H} 4_{\mathrm{a}}$ & Financial reward $\rightarrow$ Job satisfaction $\rightarrow$ Employee loyalty & 0.156 & 0.033 & 4.764 & 0.000 & Supported \\
$\mathrm{H} 4_{\mathrm{b}}$ & Non-financial reward $\rightarrow$ Job satisfaction $\rightarrow$ Employee & 0.332 & 0.054 & 6.194 & 0.000 & Supported \\
& loyalty & & & & & \\
\hline
\end{tabular}

\subsection{Discussion}

\subsection{Reward and job satisfaction}

The result found that $\mathrm{H}_{\mathrm{a}}$ and $\mathrm{H} 1_{\mathrm{b}}$ are supported. Daily tasks in the hospitality industry are heavy, involve long hours with low pay. These characteristics of the industry appear demotivating from the start. Hence, the usage of reward tools is able to lift employee satisfaction in the industry (Hartigan, 2015). The finding is similar to past studies conducted in other countries using the same variables. In addition, Seng and Arumugam (2017) claimed that the majority of hospitality employees in Malaysia are unsatisfied with their monthly salary. Thus, financial reward is highly required to cover insufficient salary in ever-rising cost of living. Apart from that, as competition for wages intensifies in the hospitality industry, a recognition system helps to provide job satisfaction and reduce turnover intention (Hartigan, 2015). After fulfilling the lower-level needs such as basic physiological needs (food and shelter) and safety (financial security), usually, human beings will yearn for self-esteem needs (recognition), as illustrated in Maslow's Hierarchy of Needs. The result was consistent with the previous studies eventhough the studies were conducted in various settings with different cultural backgrounds (Hartigan, 2015; Jafri, 2015; Jose, 2015; Met \& Huang, 2016; Seng \& Arumugam, 2017; Tirta \& Enrika, 2020).

\subsection{Reward and employee loyalty}

The study found the influence of financial reward on employee loyalty, thus supporting $\mathrm{H}_{2}$. This finding is aligned with past studies which tested the effect between reward and loyalty (Akunda et al., 2018; Oshi \& Enyia, 2017). Nonetheless, $\mathrm{H} 2 \mathrm{~b}$, which tested the influence of non-financial reward on employee loyalty, was not supported. Reward is a sensitive and concerning topic for hotel employees. They want a fair reward for their contribution, or else they may seek other opportunities elsewhere. With a high standard of living in a major state such as Selangor, employees will be aiming for financial reward for their contribution to the hotel. As discussed 
previously, the non-financial reward influenced job satisfaction. However, still, it is not enough to keep employees loyal, as demonstrated in this study. Eventhough the current research does not support the influence of non-financial reward on employee loyalty, perhaps an improve non-financial reward is able to not only increase job satisfaction, more importantly, retain hotel employees. This is based on the study by Sihombing and Berlianto (2017), who claimed reward is one of the contributing factors to job satisfaction. The author also stated that job satisfaction is a vital factor in influencing employee loyalty, thus if job satisfaction is fulfilled, employees are more likely loyal and retain in the company.

\subsection{Job Satisfaction and employee loyalty}

The result demonstrated that job satisfaction influenced employee loyalty, hence $\mathrm{H} 3$ is supported. Similarly, past studies also supported the influence of job satisfaction on employee loyalty (Antonova, 2016; Farrukh, M. et al., 2020). This finding is reflected through the service-profit chain concept developed by Heskett, Jones, Loveman, Sasser, and Schlesinger (1994). The concept explained that employee satisfaction, employee loyalty, productivity, customer loyalty, and profitability are related. In a service industry such as hotels, employees act as advocates to the customer of the organisation's product, service and image. Hence, when employees are satisfied, they are more encouraged and motivated to positively promote the organisation's product, service, and image (Preko \& Adjetey, 2013). Moreover, loyal employees are also a great asset to a company. They will take care of customers effectively, understand customer demand and deliver it (Huang, 2017; Michlitsch, 2000).

\subsection{Mediating role of job satisfaction}

The indirect effect found that $\mathrm{H}_{4}$ and $\mathrm{H} 4$ b are supported in which job satisfaction significantly mediates the relationship between reward and employee loyalty. There are not many past studies that came exactly closed to the finding of this study. However, the notable one is from Jawaad et al. (2019), who found that job satisfaction mediated the relationship between reward and employee commitment. Other past studies also found significant role of job satisfaction as a mediator in the relationship between reward and turnover intention among private higher learning employees in Malaysia (Amin \& Hamid, 2016) and in the relationship between financial motivation and job performance among oil and gas employees in Malaysia (Met \& Ali, 2015).

\subsection{Conclusion and Recommendation}

In conclusion, this study explained how reward helps to satisfy employees, thus boosting their loyalty towards hotel organisations. In general, the finding showed that reward is the right tool to increase job satisfaction and loyalty among hotel employees. Management is encouraged to understand the characteristics of employees from every generation and develop reward tools that fit the expectations of all generations, thus boost job satisfaction.

Nonetheless, the study came with several limitations, which can be addressed in future research. First, the study was conducted among hotel employees in five-star hotels in Selangor. Future research is suggested to focus on other group of samples such as millennials or Generation Z who soon become major workforce in the industry and have different work attitudes and loyalty. Moreover, future research can be conducted on other types of lodging such as budget hotels (two-stars hotels and below) which may have different capabilities or methods in providing reward.

\subsection{Paper Contribution to Related Field of Study}

This study provides insights on the effectiveness of reward (financial and non-financial) in shaping employee behaviour towards organisation. Financial reward, specifically salary raise demonstrated as an important factor in promoting employee loyalty in the hospitality industry. Nonetheless, due to Covid-19 pandemic, many hotels are unable to provide financial reward due to financial constraint. Thus, hotel managers are encouraged to utilise non-financial reward such as recognition practice to sustain employees during this difficult period. Additionally, the recognition practice could be enhanced through a structured recognition program conducted officially, ceremonially and on a fixed schedule (semi-annually or quarterly basis). Apart from work performance, organisations can also recognise personal milestones such as work anniversary or birthday. An improved recognition practice can create employee's sense of belonging towards the organisation.

\section{References}

Akunda, D., Chen, Z., \& Gikiri, S. N. (2018). Role of HRM in talent retention with evidence. Journal of Management and Strategy, 9(2), 8. https://doi.org/10.5430/jms.v9n2p8 Bustamam, F. L., Teng, S. S., \& Abdullah, F. Z. (2014). Reward management and job satisfaction among frontline employees in hotel industry in Malaysia. Procedia - Social and Behavioral Sciences, 144, 392-402. https://doi.org/10.1016/j.sbspro.2014.07.308

Chen, Y. C., Tsui, P. L., \& Lee, C. S. (2017). The effect of international hotel employee loyalty on customer behavioral intention in Taiwan. International Journal of Managerial Studies and Research, 5(2). https://doi.org/10.20431/2349-0349.0502008

Cholli, C., Sreeraj, P. S., \& Pandey, S. (2017). To study the factors of absenteeism in hospitality sector in India. Imperial Journal of Interdisciplinary Research, 3(2), 524533. http://www.onlinejournal.in 
Cook, J., \& Wall, T. (1980). New work attitude measures of trust, organisational commitment and personal need non-fulfilment. Journal of Occupational Psychology, 53(1), 39-52. https://doi.org/10.1111/j.2044-8325.1980.tb00005.x

Dwesini, N. F. (2019). Causes and prevention of high employee turnover within the hospitality industry: A literature review. African Journal of Hospitality, Tourism and Leisure, 8(3), 1-15. https://www.ajhtl.com

Farrukh, M., Kalimuthu, R., \& Farrukh, S. (2019). Impact of job satisfaction and mutual trust on employee loyalty in Saudi hospitality industry: A mediating analysis of leader support. International Journal of Business and Psychology, 1(2), 30-52. http:/lijbpsy.com

Farrukh, M., Kalimuthu, R., Farrukh, S., \& Khan, M. S. (2020). Role of job satisfaction and organisational commitment in employee loyalty: Empirical analysis from Saudi hotel industry. International Journal of Business and Psychology, 2(1), 1-20.

Fathy, E. A. (2018). Issues faced by hotel human resource managers in Alexandria, Egypt. Research in Hospitality Management, 8(2), 115124. https://doi.org/10.1080/22243534.2018.1553381

Fornell, C., \& Larcker, D. F. (1981). Evaluating structural equation models with unobservable variables and measurement error. Journal of Marketing Research, 18(1), 39. https://doi.org/10.2307/3151312

Garson, G. D. (2016). Partial least squares: Regression \& structural equation models. Statistical Associates Publishing.

Hair, J. F., Hult, G. T., Ringle, C., \& Sarstedt, M. (2017). A primer on partial least squares structural equation modeling (PLS-SEM). SAGE Publications.

Henseler, J., Ringle, C. M., \& Sarstedt, M. (2015). A new criterion for assessing discriminant validity in variance-based structural equation modelling. Journal of the Academy of Marketing Science, 43(1), 115-135.

Henseler, J., Ringle, C. M., \& Sinkovics, R. R. (2009). The use of partial least squares path modeling in international marketing. Advances in International Marketing, 20, 277-319. https://doi.org/10.1108/S1474-7979(2009)0000020014

Jawaad, M., Amir, A., Bashir, A., \& Hasan, T. (2019). Human resource practices and organisational commitment: The mediating role of job satisfaction in emerging economy Cogent Business \& Management, 6(1), 1608668. https://doi.org/10.1080/23311975.2019.1608668

Mahidin, M. U. (2020). Tourism satellite account 2019. Department of Statistics

Malaysia. https://www.dosm.gov.my/v1/index.php?r=column/cthemeByCat\&cat=111\&bul_id=dEZ6NOdYUDJEWkVxMzdOalY3UUJSdz09\&menu_id=TE5CRUZCblh4ZTZ MODZlbmk2aWRRQT09

Oshi, E. O., \& Enyia, C. D. (2017). Examining how monetary and non-monetary rewards can influence voluntary and involuntary turnover in fast-food restaurants in Port Harcourt. IIARD International Journal of Economics and Business Management, 8(4).

Strenitzerová, M., \& Achimský, K. (2019). Employee satisfaction and loyalty as a part of sustainable human resource management in postal sector. Sustainability, 11(17) 4591. https://doi.org/10.3390/su11174591

Thi Kim Phuong, T., \& Trung Vinh, T. (2020). Job satisfaction, employee loyalty and job performance in the hospitality industry: A moderated model. Asian Economic and Financial Review, 10(6), 698-713. https://doi.org/10.18488/journal.aefr.2020.106.698.713

Tirta, A. H., \& Enrika, A. (2020). Understanding the impact of reward and recognition, work life balance, on employee retention with job satisfaction as mediating variable on millennials in Indonesia. Journal of Business \& Retail Management Research, 14(03). https://doi.org/10.24052/jbrmr/v14is03/art-09

Tomic, I., Tesic, Z., Kuzmanovic, B., \& Tomic, M. (2018). An empirical study of employee loyalty, service quality, cost reduction and company performance. Economic Research-Ekonomska Istraživanja, 31(1), 827-846. https://doi.org/10.1080/1331677x.2018.1456346

Weiss, D., Dawis, R. V., England, G. W., \& Lofquist, L. H. (1967). Minnesota satisfaction questionnaire-long form. PsycTESTS Dataset. https://doi.org/10.1037/t05540-000

Wong, K. K. (2019). Mastering partial least squares structural equation modeling (pls-sem) with Smartpls in 38 hours. iUniverse.

Ya-Hsin, C., \& Hung-Sheng, H. S. (2017). The effects of training and reward systems on employee willingness to stay - A case study of an international tourist hotel in Taipei. International Journal of Research in Tourism and Hospitality, 3(1). doi:10.20431/2455-0043.0301003

Yong, S. H. (2019, October 30). Tending to the tourism goose. NST Online. https://www.nst.com.my/opinion/columnists/2019/10/534213/tending-tourism-goose 